\title{
Garantías de no repetición y reformas legislativas: causas de la falta de pronunciamiento y denegación de reparaciones en la jurisprudencia de la Corte Interamericana de Derechos Humanos a partir del caso Cinco Pensionistas vs. Perú**
}

\section{Guarantees of non-repetition and legislative reforms: Causes of the lack of pronouncement and denial of reparations in the jurisprudence of the Inter-American Court of Human Rights from the case of Case of the Five Pensioners vs. Peru}

RESUMEN

Las garantías de no repetición han supuesto un importante avance para las víctimas de violaciones a derechos humanos en la región, en especial aquellas que tienen relación con reformas a la legislación interna, dado que su principal objetivo es generar cambios estructurales en un Estado. Este trabajo presenta un estudio jurisprudencial sobre el comportamiento de la Corte IDH ante la solicitud de esta clase de reparaciones, a partir del caso Cinco Pensionistas vs. Perú, caso que marca el inicio de uno de los cambios reglamentarios más importante ante el sistema interamericano vinculado a la mayor participación de las víctimas en el proceso ante la CIDH y la Corte IDH.

Profesora de Derecho Internacional Público, Facultad de Derecho, Universidad Diego Portales (Santiago, Chile). Estudiante del Doctorado en Derecho y magíster en Derecho Internacional de los Derechos Humanos por la Universidad Diego Portales. Correo electrónico: marcela. zunigar@mail.udp.cl orCID: https://orcid.org/0000-0002-7308-4490

Recibido el 4 de enero del 2019, aprobado el 28 de enero del 2020.

Para citar el artículo: ZúÑIGA REYEs M. Garantías de no repetición y reformas legislativas: causas de la falta de pronunciamiento y denegación de reparaciones en la jurisprudencia de la Corte Interamericana de Derechos Humanos a partir del caso Cinco Pensionistas vs. Perú. En Revista Derecho del Estado, Universidad Externado de Colombia. N. ${ }^{\circ} 46$, mayo-agosto de 2020, pp. 25-55.

DOI: https://doi.org/10.18601/01229893.n46.02 
Bajo este contexto, se entrega un marco teórico sobre este tipo de reparaciones y sus principales dificultades de implementación al interior de los Estados para luego dar a conocer los resultados del análisis jurisprudencial.

PALABRAS CLAVES

Reparaciones, garantías de no repetición, responsabilidad internacional, reforma de la ley, Sistema Interamericano de Derechos Humanos.

\section{ABSTRACT}

The guarantees of non-repetition have been an important step forward for victims of human rights violations in the region, especially those related to reforms to domestic legislation, given that their main objective is to generate structural changes in a State. This paper presents a jurisprudential study on the behavior of the IHR Court in response to the request for this type of reparations, based on the case Five Pensioners vs. Peru, a case that marks the beginning of one of the most important regulatory changes before the Inter-American system linked to the greater participation of victims in the process before the IACHR and the Inter-American Court.

In this context, a theoretical framework is provided on this type of reparations and its main difficulties of implementation within the States, to then make known the results of the jurisprudential analysis giving an account of the argumentative line of the Inter-American Court and the reasons that has established to deny this type of repairs.

\section{KEYWORDS}

Reparations, Guarantees of non-repetition, International Responsibility, Human Rights, Reform of the law, Inter-American Human Rights System.

SUMARIO

Siglas y abreviaturas utilizadas. Introducción. 1. Reparaciones en el SIDH y modificaciones legislativas como garantía de no repetición. 1.1 Garantías de no repetición: reparaciones que involucran reformas legislativas. 2. Causas de la denegación de reparaciones en la jurisprudencia de la Corte IDH a partir del caso Cinco Pensionistas vs. Perú. 2.1 Casos en que la Corte IDH no se ha pronunciado respecto a la solicitud de garantías de no repetición como formas de reparación que involucran la creación, modificación y/o derogación de normas (periodo 2003 a 2006 y posteriores a 2010) 2.2 Casos en que la Corte IDH no dio lugar a la solicitud de garantías de no repetición en materia legislativa. Conclusiones. Referencias. 
SIGLAS Y ABREVIATURAS UTILIZADAS

GNR

DDHH

Corte IDH

$\mathrm{CIDH}$

$\mathrm{CADH}$

SIDH

CID
: Garantías de no repetición

: Derechos Humanos

: Corte Interamericana de Derechos Humanos

: Comisión Interamericana de Derechos Humanos

: Convención Americana sobre Derechos Humanos

: Sistema Interamericano de Derechos Humanos

: Comisión de Derecho Internacional

\section{INTRODUCCIÓN}

Una de las materias que ha suscitado amplios comentarios a lo largo del desarrollo del Sistema Interamericano de Derechos Humanos (en adelante SIDH) es la obligación de reparar a las víctimas ${ }^{1}$. Esta obligación ha sido objeto de una importante evolución en las últimas décadas, diversificando sus modalidades, cuestión que ha dependido de lo ordenado por la Corte IDH y del tipo de violación que se trate ${ }^{2}$.

Aquellas reparaciones que involucran una modificación a nivel legislativo, se enmarcan en la categoría de garantía de no repetición (en adelante GNR), consistentes en medidas que el Estado debe implementar a nivel normativo o institucional, tendientes a prevenir la recurrencia de violaciones a los derechos humanos ${ }^{3}$. Estas medidas van desde la adecuación de la legislación interna de un Estado, la derogación de normas, tipificación de delitos hasta la declaración de nulidad de leyes ${ }^{4}$.

Estas intentan corregir un error de tipo estructural identificado al examinar un caso $^{5}$, cuestión que se encuentra respaldado por el artículo $2^{\circ}$ de la $\mathrm{CADH}$ que obliga a los Estados a adoptar medidas legislativas (entre otras) para

1 BAZÁN, Víctor. Las reparaciones en el Derecho Internacional de los Derechos Humanos, con particular referencia al Sistema Interamericano. En Anuario Argentino de Derecho Internacional de la Asociación Argentina de Derecho Internacional. Editorial Lerner, 2010. ISBN 978-987-1579-37-2, p. 268.

2 Jiménez de Aréchaga. Responsabilidad internacional. En Sorensen, M., Manual de Derecho Internacional Público. Editorial Fondo de Cultura Económica. México, D.F., 1985. ISBN 9789681602161, pp. 508-513.

3 Ministerio Público Fiscal de la Ciudad Autónoma de Buenos Aires. Diálogos: el impacto del Sistema Interamericano en el ordenamiento interno de los Estados. Editorial Eudeba. Ciudad Autónoma de Buenos Aires, Argentina. 2013. ISBN 978-950-23-2229-2, p. 442.

4 Nash, Claudio. Las Reparaciones ante la Corte Interamericana de Derechos Humanos (1988-2007). Segunda Edición corregida y actualizada. Facultad de Derecho Universidad de Chile. Santiago. 2009. ISBN 978-956-19-0636-5, p. 65.

5 Schönsteiner, Judith. Dissuasive measures and the 'society as a whole': A working theory of reparations in the Inter-American Court of Human Rights. American University International Law Review, v. 23 n.1. 2015, p. 149. 
adecuar el ordenamiento interno a esta ${ }^{6}$. Un ejemplo del impacto de estas reparaciones es el caso de la Última Tentación de Cristo (Olmedo Bustos y otros) vs. Chile, en que el fallo de la Corte IDH generó la reforma constitucional $\mathrm{N}^{\circ} 19.742$, que eliminó la censura previa y la reemplazó por un sistema de calificación cinematográfica. El caso se refiere a la responsabilidad del Estado debido a la censura judicial impuesta a la exhibición de la película con el mismo nombre, por parte del Consejo de Calificación Cinematográfica. La garantía de no repetición ordenada por la Corte IDH consistió en que en razón de la vulneración al artículo 13 de la CADH que regula el derecho de libertad de expresión "el Estado debe modificar su ordenamiento jurídico con el fin de suprimir la censura previa, para permitir la exhibición cinematográfica y la publicidad de la película La Última Tentación de Cristo"7.

Otro caso que corrigió un error estructural fue Barrios Altos vs. Perú referida a las denominadas leyes de auto - amnistía. La Corte IDH declaró que "las leyes de amnistía No. 26.479 y 26.492 "son incompatibles con la Convención $[\ldots]$ y, en consecuencia, carecen de efectos jurídicos" ${ }^{\text {. }}$. Esta sentencia ha sido reconocida como "una de las más emblemáticas en cuanto al combate a la impunidad y la perpetuidad de la misma en el tiempo, y sobre los deberes y límites que tienen los Estados respecto a la investigación de casos de graves violaciones de derechos humanos".

Derivado del impacto que significa para el ejercicio de la soberanía nacional de un Estado, estas medidas son controvertidas desde la mirada del derecho internacional clásico, en el cual hasta hace poco tiempo era impensable que un órgano internacional pudiera intervenir con tal intensidad en un Estado ${ }^{10}$. Por tal motivo, están en su mayoría pendientes de cumplimiento, revelando con ello la resistencia interna del Poder Legislativo ${ }^{11}$ de acatar lo impuesto por la Corte IDH. Esto ha sido respaldado por estudios que han revelado que el existe

6 CAssel, Douglass. The Expanding Scope and Impact of the reparations awarded by the Interamerican Court of Humans Rights. Revista do Instituto Brasileiro de Direitos Humanos. 2010, Vol. 7, n. ${ }^{\circ}$, p. 92.

7 Corte IDH, Caso La última tentación de Cristo vs. Chile, Sentencia de Reparaciones y Costas de 1998, párr. 97.

8 Corte IDH, Caso Barrios Altos vs. Perú. Sentencia de Fondo de 2001, punto resolutivo 4.

9 SaAvedra, Pablo. Algunas reflexiones en cuanto al impacto estructural de las decisiones de la Corte Interamericana de Derechos Humanos. En Ferrer Mac-Gregor, Eduardo Von Bogdandy, Armin Morales Antoniazzi, Mariela (Coordinadores). Ius Constitutionale Commune en América Latina. Textos básicos para su comprensión. Colección Constitución y Derechos. Instituto de Estudios Constitucionales del Estado de Querétaro - Max Planck Institute for Comparative Public Law and International Law. México. 2017. ISBN 978-607-7822-32-5, p. 484.

10 Cassel, Douglass. Cit., p. 95.

11 Correa, Cristian. Reparaciones y medidas provisionales. En Convención Americana sobre Derechos Humanos. Fundación Konrad Adenauer (Eds.). Santiago de Chile. ISBN 978-9567684-11-3. 2013, p. 846. 
un cumplimiento de estas medidas que va de entre el $5 \%^{[12]}$ al $14 \%{ }^{[13]}$. Esta fluctuación se debe a que la definición de las categorías que involucran este tipo de reparación tiende a ser abordada de forma diferente en cada estudio.

No obstante, es posible observar que a partir del caso Cinco Pensionistas vs. Perú si bien los representes de las víctimas y/o la CiDH solicitaron reparaciones que involucran modificaciones legislativas, la Corte IDH en varios casos no se ha pronunciado o las ha denegado sin fundamentar los motivos o las ha denegado en virtud de una serie de argumentaciones que van desde aspectos de fondo a cuestiones de índole procesal.

En consecuencia, esta investigación presenta un estudio del comportamiento de la Corte IDH ante las solicitudes de esta clase de reparaciones a partir de la revisión, sistematización y análisis de las sentencias en que exista una solicitud de adoptar tales medidas por parte de los representantes de las víctimas y/o de la CIDH. Lo anterior desde la sentencia señalada hasta diciembre de 2016.

Para cumplir este objetivo, el trabajo consta de dos apartados y una conclusión. El primero describirá y analizará el concepto de GNR para luego profundizar acerca de las reparaciones que tienen vinculación con la modificación, derogación y/o creación de normas.

En el segundo capítulo, se mostrarán los resultados de la sistematización y análisis de las sentencias en que tanto los representantes de las víctimas como la CIDH, de manera individual o conjunta, solicitaron este tipo de reparaciones. Esto con el objetivo de ilustrar el comportamiento de la Corte IDH y presentar los resultados de la investigación y sus respectivas conclusiones.

La relevancia de este estudio radica en el impacto de estas reparaciones ya que buscan generar un efecto preventivo de futuras violaciones frenando con ello el efecto sistemático que pueden generar si no son implementadas por los Estados. Por ello, conocer los motivos por los cuáles la Corte IDH no las ha ordenado puede ayudar a generar mayores estudios para fortalecer su eficacia en el sistema.

1. REPARACIONES EN EL SISTEMA INTERAMERICANO DE DERECHOS HUMANOS Y MODIFICACIONES LEGISLATIVAS COMO GARANTÍAS DE NO REPETICIÓN

La responsabilidad de los Estados por violación a derechos humanos en el SIDH tiene asidero sobre la teoría del derecho internacional público que establece como principio general el que todo hecho internacionalmente ilícito

12 Hawkins Darren y Jacoby W Ade. Partial Compliance: A comparison of the European and Inter- American Courts of Human Rights. Paper presented at the annual meeting of the APSA 2008 Annual Meeting, Hynes Convention Center, Boston, Massachusetts. 2008, p. 6.

13 Baluarte David C y De Vos Christian. From Judgment to Justice: Implementing International and Regional Human Rights Decisions. Open Society Justice Initiative. ISBN 9781-936133-33-8. 2010, p. 68. 
cometido por un Estado genera su responsabilidad ${ }^{14}$. A partir de esta premisa emerge una nueva situación jurídica para el Estado infractor, regida por un conjunto de normas que regula las condiciones para el surgimiento de tal responsabilidad, su contenido o consecuencias (obligaciones secundarias) ${ }^{15}$.

Así, la Comisión de Derecho Internacional articuló el marco jurídico a través de los artículos sobre responsabilidad del Estado por hechos internacionalmente ilícitos, aprobados por la Asamblea General de las Naciones Unidas en 2001. Este trabajo "es completamente válido para el sIDH que, en su esfuerzo por contribuir a la promoción y protección de los derechos humanos en la región, ha creado con la CADH un régimen interestatal especial de derechos y obligaciones sobre esta temática, aunado a un mecanismo particular para hacer exigibles los compromisos adquiridos por los Estados parte a favor de todos los habitantes del continente" 16 . De este modo, a partir de sus primeros casos la Corte IDH ha establecido que la obligación de reparar contenida en la CADH, es de derecho internación público, por lo que éste rige todos sus aspectos, esto es, su extensión, sus modalidades, sus beneficiarios, etc. ${ }^{17}$

Tomando estos principios generales, existe la premisa de que a partir de la declaración de responsabilidad internacional surge para el Estado la obligación de reparar a la víctima de un caso. En el sIDH, esta obligación se desprende del artículo 63.1 de la CADH, norma de carácter consuetudinario que se constituye como uno de los principios fundamentales del derecho internacional sobre la responsabilidad de los Estados ${ }^{18}$. Esta norma establece que, cuando se decida que hubo violación de un derecho o libertad protegidos en la CADH, "la Corte dispondrá que se garantice al lesionado en el goce de su derecho o libertad conculcados. Dispondrá, asimismo, si ello fuera procedente, que se reparen las consecuencias de la medida o situación que ha configurado la vulneración de esos derechos y el pago de una justa indemnización a la parte lesionada".

La reparación del daño consiste en la plena restitución, entendiendo como tal "el restablecimiento de la situación anterior y la reparación de las consecuencias que la infracción produjo y el pago de una indemnización como compensación por los daños patrimoniales y extra patrimoniales incluyendo

14 Organización de las Naciones Unidas, Comisión de Derecho Internacional, Proyecto de artículos sobre responsabilidad del Estado por hechos internacionalmente ilícitos, adoptados por la CDI en su $53^{\circ}$ periodo de sesiones (A/56/10) y anexado por la AG en su resolución 56/83, de 12 de diciembre de 2001, artículo 1 .

15 Londoño, María CARMelina. Las garantías de no repetición en la jurisprudencia interamericana. Primera Edición. Editorial Tirant Lo Blanch México. ISBN 9788490537626. 2014, p. 31.

16 Ibíd.,p. 33.

17 Corte IDH, Caso Aloeboetoe y otros vs. Surinam, Sentencia de Reparaciones y Costas de 1993, párr. 44.

18 Corte IDH, Caso Trujillo Oroza vs. Bolivia, Sentencia de Reparaciones y Costas de 2002, párr. 60 . 
el daño moral" 19 . Sin embargo, el restablecimiento de la situación anterior en algunas situaciones puede resultar imposible ${ }^{20}$, por lo tanto, el objetivo del principio de restitutio in integrum es guiar las decisiones para identificar una medida de reparación que pueda en la medida de lo posible acercarse a ese ideal $^{21}$. Así, la Corte IDH reconoce otras medidas de reparación tales como "medidas compensatorias pecuniarias, medidas de restitución, satisfacción y garantías de no repetición”. Por lo tanto, el estándar que la Corte toma en cuenta al momento de decidir qué medida aplicar está en directa relación de proporcionalidad con el daño causado a la víctima en un caso. Asimismo, la Corte IDH ha tenido en cuenta tres factores para determinar las medidas de reparación: la justicia, la no repetición de los hechos y el reconocimiento público de responsabilidad o satisfacción. Estos tres factores, individualmente o combinados entre sí, contribuyen a la reparación integral por parte del Estado de la violación de sus obligaciones internacionales ${ }^{22}$.

De este modo, una de las razones que justifican esta gran variedad de reparaciones, es que la Corte ha debido ajustarse a las nuevas exigencias que cada caso ha planteado en coherencia con el concepto de interpretación evolutiva de las normas internacionales ${ }^{23}$.

Así, el sidH ha implementado un modelo de reparaciones en base al marco elaborado por sistema de Naciones Unidas, incluyendo dentro de las medidas de reparación a las denominadas garantías de no repetición. En el siguiente apartado, se describirán las principales características de este modelo, y los problemas de legitimidad que ha acarreado en la práctica al momento de implementarlas.

\subsection{Garantías de no repetición: reparaciones que involucran reformas legislativas}

La Comisión de Derecho Internacional estableció que "el Estado responsable de un hecho internacionalmente ilícito está obligado a ofrecer seguridades y garantías adecuadas de no repetición, si las circunstancias lo exigen" ${ }^{24}$.

19 Corte IDH, Caso Velásquez, Rodríguez vs. Honduras, Sentencia de Reparaciones de 198, párr. 26.

20 Corte IDH, Caso Aloeboetoe y otros vs. Surinam, Sentencia de Reparaciones y Costas de 1993, párr. 44.

21 Correa, Cristian. Cit., p. 846.

22 Ventura, Manuel. Impacto de las reparaciones ordenadas por la Corte Interamericana de Derechos Humanos y aportes a la justiciabilidad de los derechos económicos sociales y culturales. Revista IINDH, Vol. 56. 2012. ISSN 1015-5074, p. 140.

23 Rousset, JAVIER. El concepto de reparación integral en la jurisprudencia de la Corte Interamericana de Derechos Humanos. Revista Internacional de Derechos Humanos. Año I. n. ${ }^{\circ}$ 1. ISSN 2422-7188. 2011, p. 61 .

24 Organización de las Naciones Unidas, Comisión de Derecho Internacional, Proyecto de artículos sobre responsabilidad del Estado por hechos internacionalmente ilícitos, adoptados 
De este modo, las garantías de no repetición corresponden a una obligación secundaria autónoma en el régimen de responsabilidad internacional de los Estados por hechos ilícitos ${ }^{25}$.

La autonomía que ostentan se refleja en la clasificación que hace la CDI de las reparaciones, ya que el artículo $34^{\circ}$ del proyecto de artículos, referido a las formas de reparación, no hace alusión a ellas como una forma de reparación: "La reparación íntegra del perjuicio causado por el hecho internacionalmente ilícito adoptará la forma de restitución, de indemnización y de satisfacción, ya sea de manera única o combinada, de conformidad con las disposiciones del presente capítulo".

El sistema de Naciones Unidas reconoce su autonomía y amplio alcance, a través de los principios para los casos de graves violaciones a los derechos humanos y el derecho internacional humanitario. No obstante, estas medidas no han tenido un desarrollo importante en el derecho internacional público ${ }^{26}$, siendo estos lineamientos insuficientes para dar cuenta de sus límites y de su relación con otros conceptos, cuestión que ha generado problemas en torno a su legitimidad ${ }^{27}$.

Las garantías de no repetición han sido definidas por la doctrina como "aquellas acciones que debe desplegar el Estado en procura de que la situación que generó la violación de derechos humanos no se vuelva a presentar" 28 . En el mismo sentido, se ha determinado que para evitar que se reiteren los hechos que provocaron la violación, otra medida de reparación resultaría insuficiente ${ }^{29}$. Por tales motivos, resultan del todo relevantes considerando casos en que existen patrones recurrentes y hechos similares que importan violaciones de derechos humanos.

En materia legislativa pueden referirse a reformas o derogación de normas que resulten incompatibles con la $\mathrm{CADH}$, o bien, emisión de disposiciones compatibles, necesarias o convenientes como lo sería la tipificación de un delito $^{30}$. Se ha podido constatar que con excepción del caso Castillo Petruzzi

por la CDI en su $53^{\circ}$ periodo de sesiones (A/56/10) y anexado por la AG en su resolución 56/83, de 12 de diciembre de 2001, artículo 30.

25 Londoño, María Carmelina, Las Garantías de no repetición en la jurisprudencia interamericana. Cit., p. 23. Véase también en Crawford, James. Los artículos de la Comisión de Derecho Internacional sobre la Responsabilidad internacional del Estado: introducción, texto y comentarios. Madrid, Dykinson, S.L. 2004, p, 244.

26 Ibíd.,p. 90.

27 Ibíd.,pp. 23-24.

28 Cubides Molina, J.M. Reparaciones en la Corte Interamericana de Derechos. Revista Razón Crítica, n. ${ }^{\circ}$ 1. 2016. IssN: 2500-7807, p. 9.

29 Loianno, Adelina. Evolución de la doctrina de la Corte Interamericana de Derechos Humanos en materia de reparaciones. Revista Iberoamericana de Derecho Procesal Constitucional, n. ${ }^{\circ}$ 8. 2007. ISSN 1870-8390, p. 23.

30 García Ramírez, Sergio. Las reparaciones en el sistema interamericano de protección de los derechos humanos en el Sistema Interamericano de protección de los derechos humanos en el umbral del siglo xxI. Memoria del Seminario, realizado los días 23 y 24 de noviembre de 
vs. Perú y Loayza Tamayo vs. Perú, la Corte IDH comenzó a ordenarlas a partir del año 2001, aumentando su frecuencia desde el año 2005, en el cual se dictaminaron a nueve Estados en diez $\operatorname{casos}^{31}$. Entre las razones que pueden explicar que la Corte IDH comenzara a ordenarlas a partir del año 2001, se encuentra el cambio en su reglamento que permitió que las víctimas presentaren sus propios argumentos durante el proceso ante la Corte ${ }^{32}$.

Por otro lado, han encontrado respaldado en el artículo $2^{\circ}$ de la CADH, que estipula el deber de adoptar disposiciones de derecho interno, en medidas de acción y revisión legislativa, investigación y acción judicial, y acción ejecutiva. Al respecto, se ha señalado que, al litigar un caso, hay que analizar si una violación se basa en la aplicación de leyes específicas que no son compatibles con la CADH. En esos casos, "la reparación completa puede ocurrir y ser efectiva sólo cuando el Estado ajusta sus leyes domésticas [...] $\mathrm{Al}$ impugnar el incumplimiento de los actos normativos con la Convención, podemos obtener justicia en el caso específico, pero también en otros casos en que la violación se basa en la misma ley interna, puede evitar que se produzcan nuevas violaciones" ${ }^{\prime 3}$.

En la actualidad, la Corte IDH ha establecido límites al momento de declararlas: a) la competencia de la Corte IDH no tiene por objeto la revisión de las legislaciones nacionales en abstracto, sino que es ejercida para resolver casos concretos en que se alegue que un acto del Estado, ejecutado contra personas determinadas, es contrario a la Convención ${ }^{34}$; b) la Corte IDH no puede pronunciarse sobre solicitudes de modificaciones legales si durante el proceso no se estableció que las violaciones habían sido cometidas como resultado de deficiencias en ella ${ }^{35}$.

La Corte IDH ha ordenado cambios legislativos sólo cuando la norma en cuestión se aplicó en perjuicio de la víctima del caso, existiendo disidencias al respecto entre los jueces ${ }^{36}$. Además, ha señalado que mientras el Estado no

1999. Tomo $1.2^{\circ}$ Edición. Corte Interamericana de Derechos Humanos, San José de Costa Rica. 2003. ISBN: 9977-36-118-5, p. 152.

31 Galván Puentes, Sofía. Legislative measures as guarantees of non-repetition: a reality in the Inter-American Court, and a possible solution for the European Court. Revista IIDH. Vol. 49. 2009. ISSN 1015-5074, p. 69.

32 SCHÖNSTEINER, JUDITH. Hacia mayor seguridad jurídica en la protección regional de los Derechos Humanos: Las reformas procesales en el Sistema Interamericano. Anuario de Derecho Público. Ediciones Universidad Diego Portales. Santiago, Chile. 2010. ISBN 978-956-314-228-0, p. 293.

33 Ayala, Carlos et Al. Conference: Reparations in the Inter-American System: A Comparative Approach Conference. American University Law Review, Vol. 56, Issue 6. 2007. ISSN 1375-1468, p. 1414.

34 Corte IDH, Caso Vélez Loor vs. Panamá, Sentencia de Excepciones Preliminares, Fondo, Reparaciones y Costas de 2010, párr. 285.

35 Corte IDH, Caso Atala Riffo e Hijas vs. Chile, cit., párr. 279-280.

36 Véase voto disidente Juez Cançado Trindade en Caso El Amparo vs. Venezuela. Citado en: CASSEL, Douglass. The Expanding Scope and Impact of the reparations awarded by the Interamerican Court of Human Rights. Cit. 
modifica las normas contrarias a la Convención, debe abstenerse de aplicarlas ${ }^{37}$, principalmente en aquellos casos que se han aplicado leyes de amnistía ${ }^{38}$.

Un estudio realizado en el 2010 dio cuenta que se trata de medidas de reparación que ostentan unos de los menores grados de cumplimiento por parte de los Estados ${ }^{39}$. Los motivos de este comportamiento estatal pueden estar dados por que la mayoría de las medidas tratan de cambios estructurales, en los cuales el impacto de la voluntad política es relevante ${ }^{40}$. De esta manera, las reformas legislativas representan una zona gris y la Corte IDH es consciente de que no puede ocupar el espacio de las instituciones del Estado que tienen que llevar adelante esos cambios ${ }^{41}$.

No obstante, existen otras reparaciones que revelan menores porcentajes de cumplimiento. Investigaciones han señalado que las reparaciones que ordenan la investigación y sanción de los responsables por una determinada violación arrojan porcentajes de cumplimiento del 3\% ${ }^{[42]}$. Al tratarse de medidas que involucran la participación de varios actores estatales, los niveles de cumplimiento tienden a ser bajos, aspecto que resalta Huneeus al señalar que aquellas medidas que involucran la participación del Poder Ejecutivo, Ministerio Público y Poder Judicial, arrojan porcentajes de cumplimiento de alrededor de $2 \%$ [43].

Por otro lado, se ha constatado que por lo general los representantes de las víctimas encuentran enormes dificultades para impulsar el cumplimiento, lo que incluye numerosas negociaciones con diferentes sectores y organismos del Estado, cuestión que muchas veces entorpece y dificulta su implementación ${ }^{44}$. Como señala Shelton, "las garantías de no repetición, como las medidas de

37 Corte IDH, Caso Hilaire, Constantine y Benjamín y otros vs. Trinidad y Tobago, Sentencia de Fondo, Reparaciones y Costas de 2002, párr. 212.

38 Corte IDH, Caso Barrios Altos vs. Perú, Interpretación Sentencia de Fondo de 2001, párr. 16.

39 Basch, Fernando et al. La Efectividad del Sistema Interamericano de Protección de DDHH: Un Enfoque Cuantitativo sobre su Funcionamiento y sobre el Cumplimento de sus Decisiones. Revista Sur. Edición Vol. 7 - n. ${ }^{\circ}$ 12. 2010. ISSN 1806-6445, p. 19.

40 Beristain, CARLOS. Diálogos sobre reparación: qué reparar en casos de violaciones a derechos humanos. Instituto Interamericano de Derechos Humanos. San José, Costa Rica. 2010. ISBN: 978-9978-92-738-0, p. 374.

41 Ibíd.,p. 375.

42 GonzÁLEZ, Damián. Do States comply with the compulsory judgments of the InterAmerican Court of Human Rights? An empirical study of the compliance with 330 measures. Revista do Instituto Brasileiro de Direitos Humanos. Vol. 13, n. ${ }^{\circ}$ 13. 2013. ISSN 1677-1419, p. 107.

43 Huneeus, AleXANDRa. Courts Resisting Courts: Lessons from the Inter-American Court's Struggle to Enforce Human Rights. Cornell International Law Journal. Vol. 44. Issue. 3. Article 2. 2011 ISSN: 0010-8812, p. 509.

44 Idem. 
satisfacción, son vistas como inapropiadas a nivel interestatal, pero son muy importantes en los casos de derechos humanos" ${ }^{45}$.

Una investigación realizada en 2010, en la que se entrevistó a 207 personas entre actores estatales, sociedad civil y víctimas, constató que, en ocasiones, las dificultades en la práctica se relacionan con las dudas expresadas por algunos agentes del Estado sobre la legitimidad de las GNR como parte de una sentencia de la Corte. Cambiar esta perspectiva es fundamental para adecuarse a los requerimientos del derecho internacional y para mejorar el cumplimiento ${ }^{46}$. El estudio además señaló que normalmente los representantes de las víctimas pretenden que sea el mismo Estado el que declare, como medida de reparación, que la conducta que realizó es ilícita, cuando ese mismo acto u omisión resulta ser la voluntad de la mayoría política expresada en la legislación ${ }^{47}$.

Existen autores que plantean que para que el cumplimiento sea efectivo, se requiere involucrar directamente a las autoridades nacionales relevantes. Por ello, la no ejecución de las sentencias no solo tiene que ver con cuestiones de costo o falta de voluntad política, sino más bien de que existen contextos institucionales que involucran intereses políticos e ideologías dispares que deben ser considerados ${ }^{48}$.

Otros autores han establecido que una posible explicación del incumplimiento "podría estar asociada a las características de la entidad estatal a cargo de su implementación. En muchos casos el poder encargado de las relaciones exteriores estatales ante el SIDH es distinto de los poderes que deben involucrarse en la implementación de las medidas requeridas. Por ejemplo, en los casos en que se requiere la modificación de una ley, el Poder Ejecutivo puede impulsar una reforma, pero la medida sólo será cumplida mediante la intervención del Poder Legislativo, en el que, a su vez, diversas fuerzas políticas deben lograr consensos"49.

Así por ejemplo, en el caso Palamara Iribarne vs. Chile la Corte IDH ordenó "adecuar el ordenamiento jurídico interno a los estándares internacionales sobre jurisdicción penal militar, de forma tal que en caso de que considere necesaria la existencia de una jurisdicción penal militar, esta debe limitarse solamente al conocimiento de delitos de función cometidos por militares en servicio activo" ${ }^{50}$. Como es posible observar, la adecuación de la normativa

45 Shelton, Dinah. The Present Value of Past Wrong.Reparations for Indigenous Peoples. International and Comparative Perspectives. Edited by Federico Lenzerini. Oxford University Press. 2010. ISBN 9780199235605, p. 67.

46 Beristain, Carlos. Cit., p. 381.

47 Shelton, Dinah. Remedies in International Human Rights Law. Oxford University Press. 2005. 9780199207534, p. 20.

48 Huneeus, Alexandra. Cit., p. 511.

49 Basch, Fernando et al. Cit., p. 28.

50 Corte IDH, Caso Palamara Iribarne vs. Chile, Sentencia de Fondo, Reparaciones y Costas de 2005, párr. 256. 
interna implica una importante discusión en el Congreso, cuya composición ostenta un porcentaje relevante de parlamentarios pertenecientes a la derecha chilena que apoya la vigencia de la jurisdicción militar. A este tipo de obstáculos se hace referencia con la obtención de complejos consensos con los que tiene que lidiar los Estados para el cumplimiento de sentencias de la Corte.

Aunado a estas resistencias, se ha sostenido que la implementación de las órdenes del SIDH depende principalmente de la voluntad política de los actores involucrados, cuestión que comúnmente es justificada por los Estados en base a condicionamientos institucionales que suelen dificultar la ejecución de medidas, esto a pesar de existir voluntad del cumplimiento ${ }^{51}$.

Se ha establecido en la doctrina que, para facilitar su cumplimiento, éstas deben ser lo suficientemente claras como para ser entendidas y seguidas por los órganos estatales a cargo de su ejecución, como también concretas para lograr su supervisión por la Corte. Adicionalmente, un tercer elemento dice relación con su flexibilidad en el sentido de permitir al Estado cierta discreción en su implementación, ya que la Corte IDH no puede anticiparse a todas las complicaciones específicas que puedan surgir en el país durante su aplicación ${ }^{52}$.

Finalmente, cabe tener presente que la Corte IDH, mediante el seguimiento del cumplimiento de las sentencias, descrito en el artículo 69 de su reglamento, ejecuta un rol de mediadora/conciliadora con el objetivo de instar a los Estados avanzar en la implementación concreta de medidas. Esta labor se hace mediante la presentación de informes estatales y de las correspondientes observaciones a dichos informes por parte de las víctimas o sus representantes; solicitando datos provenientes de otras fuentes de información; y cuando lo considera permitente, puede convocar al Estados y a los representantes de las víctimas a una audiencia para supervisar el cumplimiento de sus decisiones, escuchando también a la $\mathrm{CIDH}^{53}$. Esta audiencia se convoca cuando ha existido algún avance en la implementación, quedando algunos puntos específicos a resolver ${ }^{54}$.

51 Schönsteiner, JUdith y JaVIER Couso. La implementación de las decisiones de los órganos del Sistema Interamericano de Derechos Humanos en Chile: ensayo de un balance. Revista de Derecho Universidad Católica del Norte. Sección de Estudios. Año 2, n. 2. 2015. ISSN 0718-9753, p. 327.

52 Antкошіак, Thomas M. Remedial Approaches to Human Rights Violations: The InterAmerican Court of Human Rights and Beyond. En Seattle University School of Law Digital Commons. 46 Colum. J. Transnat'l. L. 351.2008, p. 387.

53 Convención Americana sobre Derechos Humanos, artículo $69^{\circ}$.

54 SCHÖNSTEINER, JUdith Y JAVIER COUSO. Cit., p. 325. 
2. CAUSAS DE LA DENEGACIÓN DE REPARACIONES EN LA JURISPRUDENCIA DE LA CORTE IDH A PARTIR DEL CASO CINCO PENSIONISTAS VS. PERÚ

Para la elaboración de este apartado se sistematizaron y analizaron las sentencias de reparaciones desde el caso "Cinco Pensionistas vs. Perú" en febrero de 2003, hasta el caso "Andrade Salomón vs. Bolivia" en diciembre de 2016. Luego, se seleccionaron 103 sentencias en que tanto la CIDH como los representantes de las víctimas, de manera conjunta o separada, solicitaron como GNR la creación, modificación y/o derogación de normas para un Estado. Esto último con la intensión de identificar cuál era el tratamiento que la Corte IDH había dado a tal solicitud. La elección de las sentencias a partir del 2003 coincide con el cambio en el reglamento de la Corte IDH en que la CIDH es reconocida como representante de la presunta víctima.

A partir de este análisis, se identificaron un grupo de sentencias en que, si bien la reparación en cuestión había sido solicitada, la Corte IDH no emitió pronunciamiento en ningún sentido. Este grupo de sentencias corresponde al periodo entre 2003 a 2006 y en algunos casos a partir del 2010. Posteriormente, se constató que entre 2006 a 2016, la Corte IDH rechazó este tipo de reparaciones mediante una serie de argumentos que van desde cuestiones procesales a otras más de bien de fondo. Cabe tener a la vista que durante este periodo la Corte IDH justificó todas las negativas identificadas.

En consideración a lo anterior, este capítulo ilustrará cuál ha sido el comportamiento de la Corte IDH en una secuencia cronológica de análisis de su jurisprudencia, identificando en cuáles casos no se ha hecho cargo de las solicitudes de las partes, como también exponiendo los argumentos que ha señalado para rechazar este tipo de reparaciones entre el periodo 2003 a 2016.

\subsection{Casos en que la Corte IDH no se ha pronunciado respecto a la} solicitud de garantías de no repetición como formas de reparación que involucran la creación, modificación y/o derogación de normas (periodo 2003 a 2006 y en algunos casos a partir del año 2010)

Un primer hallazgo fue un grupo de 12 sentencias de reparaciones en que, si bien se constató que tanto los representantes de las víctimas como la CIDH, de manera conjunta o separada, solicitaron medidas legislativas como forma de reparación, la Corte IDH no se pronunció. Esta falta de pronunciamiento se puede clasificar en sentencias donde la solicitud fue realizada: 


\subsubsection{Por los representantes de la víctima}

De los casos analizados se solicitaron reparaciones en torno a adecuación de normativa a estándares internacionale ${ }^{55}$; tipificación de delito ${ }^{56}$; ratificación de tratados internacionales ${ }^{57}$; prohibir conductas en la legislación ${ }^{58}$; inclusión de normas sobre convenios internacionales ${ }^{59}$; derogación de disposiciones discriminatorias ${ }^{60}$ y reformas legales ${ }^{61}$.

Uno de los aspectos que llama la atención es que, en 7 de los 8 casos, la Corte IDH no condenó a los Estados por violación al artículo $2^{\circ}$ de la CADH. La excepción es el caso “Acosta Calderón vs. Ecuador”, en que se condenó al Estado por violación a la norma señalada en relación con el artículo 7.5 en base a las siguientes consideraciones: "En conclusión, la Corte señala que, al momento en que ocurrieron los hechos, la excepción contenida en el artículo 114 bis del Código Penal ${ }^{62}$ infringió el artículo 2 de la Convención por cuanto el Ecuador no había adoptado las medidas adecuadas de derecho interno que permitieran hacer efectivo el derecho contemplado en el artículo 7.5 de la Convención ${ }^{63} "$.

Sin embargo, la explicación a este comportamiento se vincula a que los representantes de la víctima solicitaron la derogación de una disposición legal distinta al artículo 114 bis del Código Penal, haciendo alusión además a la introducción de reformas que, si bien se refieren a temas específicos, no

55 Corte IDH, Caso Juan Humberto Sánchez vs. Honduras, Sentencia de Excepciones Preliminares, Fondo y Reparaciones de 2003; Caso Tibi vs. Ecuador, Sentencia de Excepciones Preliminares, Fondo, Reparaciones y Costas de 2004; Caso Masacre Mapiripán vs. Colombia, Sentencia de Fondo, Reparaciones y Costas de 2005; Caso Masacre Ituango vs. Colombia, Sentencia de Excepciones Preliminares, Fondo y Reparaciones de 2006.

56 Corte IDH, Caso Juan Humberto Sánchez vs. Honduras. Cit.

57 Ídem.

58 Corte IDH, Caso Hermanos Paquiyauri vs. Perú, Fondo, Sentencia de Reparaciones y Costas de 2004; Caso Gutiérrez Soler vs. Colombia, Sentencia de Fondo, Reparaciones y Costas de 2005; Caso Servellón García y otros vs. Honduras, Sentencia de Fondo, Reparaciones y Costas de 2006.

59 Corte IDH, Caso Hermanos Paquiyauri vs. Perú. Cit.

60 Corte IDH, Caso Acosta Calderón vs. Ecuador, Sentencia de Fondo, Reparaciones y Costas de 2005; Caso Masacre Ituango vs. Colombia. Cit.

61 Corte IDH, Caso Acosta Calderón vs. Ecuador. Cit.

62 El artículo 114 bis del Código Penal establecía que "Las personas que hubieren permanecido detenidas sin haber recibido auto de sobreseimiento o de apertura al plenario por un tiempo igual o mayor a la tercera parte del establecido por el Código Penal como pena máxima para el delito por el cual estuvieren encausadas, serán puestas inmediatamente en libertad por el juez que conozca el proceso. De igual modo las personas que hubieren permanecido detenidas sin haber recibido sentencia, por un tiempo igual o mayor a la mitad del establecido por el Código Penal como pena máxima por el delito por el cual estuvieren encausadas, serán puestas en libertad por el tribunal penal que conozca el proceso. Se excluye de estas disposiciones a los que estuvieren encausados, por delitos sancionados por la Ley sobre Sustancias Estupefacientes y Psicotrópicas". Esta última parte de la disposición fue la que afectó a las víctimas del caso.

63 Corte IDH, Caso Acosta Calderón vs. Ecuador. Cit., párr. 138. 
suponen una descripción respecto de su contenido: [...] "b) para "impedir que los hechos violatorios se sigan dando [...] deberán derogarse todas aquellas disposiciones que establezcan un trato discriminatorio en perjuicio de los detenidos por delitos relacionados con la Ley de Sustancias Estupefacientes y Sicotrópicas. En consecuencia, de manera particular el Estado deberá derogar y eliminar la disposición final del [artículo] 37 de la Ley de Ejecución de Penas introducido en virtud de la disposición del [artículo] 1 de la Ley 44, publicada en el Registro Oficial 218, de 18 de diciembre de 1997”; c) "el Estado tiene la obligación de introducir las reformas legales para garantizar la posibilidad de recurrir judicialmente de todo acto, emitido por cualquier autoridad, juez o tribunal, en el que se violen derechos fundamentales garantizados en la Ley, la Constitución o la Convención Americana" [...]"64.

A partir de esto, se podría concluir que los representantes de las víctimas del caso fueron imprecisos en su solicitud, no logrando convencer a la Corte IDH de la violación al artículo $2^{\circ}$ de la CADH.

\subsubsection{Por la CIDH}

En el caso La Cantuta vs. Perú, la CIDH solicitó como reparación que "el Estado adopte, en el ordenamiento interno todas las medidas necesarias para garantizar, de manera efectiva la privación de los efectos jurídicos de las Leyes No. $26.479^{[65]}$ y $26.492^{[66]}$, como resultado de su incompatibilidad con la Convención Americana" 67.

La Corte IDH estableció que el Estado incumplió la obligación contenida en el artículo $2^{\circ}$ de la Convención, en orden a adecuar su ordenamiento interno a ésta, en relación con las Leyes No. 26.479 y 26.492, pero solo respecto al periodo en que fueron aplicadas a los hechos del caso. Al respecto la Corte IDH declaró que "con posterioridad a ese periodo y en la actualidad, no ha sido demostrado que el Estado haya incumplido con dicha obligación contenida en el artículo $2^{\circ}$ de la Convención, por haber adoptado medidas pertinentes para suprimir los efectos que en algún momento pudieron generar las "leyes"

64 Ibíd., párr. 129.

65 La Ley 26.479 es una Ley de Amnistía por la que se exoneraba de responsabilidad a los militares y policías, así como también a civiles, que hubieran cometido violaciones a los derechos humanos o hayan participado en esas violaciones, entre los años 1980 y 1995.

66 Es una ley interpretativa de la Ley de Amnistía No. 26.479, que estableció que la amnistía general era de aplicación obligatoria por los órganos jurisdiccionales y alcanzaba a todos los hechos derivados u originados con ocasión o como consecuencia de la lucha contra el terrorismo desde el mes de mayo de 1980 hasta el 14 de junio de 1995 sin importar que el personal militar, policial o civil involucrado, se encontrare o no denunciado, investigado, procesado o condenado, quedando todos los casos judiciales en trámite o en ejecución archivados definitivamente.

67 Corte IDH, Caso la Cantuta vs. Perú, Sentencia de Fondo, Reparaciones y Costas de 2006. párr. 193. 
de amnistía, las cuales no han podido generar efectos, no los tienen en el presente ni podrán generarlos en el futuro [...]" ${ }^{68}$

A partir de lo anterior, se desprende que la Corte IDH si bien condenó a Perú por incumplir la obligación contenida en el artículo $2^{\circ}$, no emitió pronunciamiento respecto a la reparación solicitada por la CIDH. Esto puede ser consecuencia de que, con posterioridad al acaecimiento de los hechos del caso, dichas leyes perdieron sus efectos debido a la sentencia Barrios Altos, tal como lo esgrimieron los representantes de las víctimas: [...] "el fundamento directo y único de la nulidad de aplicación de las leyes de auto amnistía es la sentencia en al caso Barrios Altos. Una lectura normativa del ordenamiento jurídico peruano permite sostener que la orden de la Corte de que las leyes de amnistía carecen de efecto, es parte del corpus juris peruano. Además, la práctica judicial y de la propia fiscalía reafirma esta posición. En la práctica los casos en los que perpetradores de violaciones de derechos humanos han invocado las leyes de amnistía han sido resueltos, declarándose la carencia de efecto de las leyes de amnistía [...]"69.

Llama la atención en este caso que la CIDH no haya tenido a la vista lo esgrimido por los representantes de las víctimas, teniendo en consideración que el caso "Barrios Altos vs. Perú" data del año 2001. Esto es una conducta inesperada dada la posición de garante interamericano que ostenta la CIDH en el sistema.

\subsubsection{Por la CIDH y los representantes de la víctima en forma conjunta}

De los casos analizados, esta situación se observó en tres casos. El primero de ellos fue García Asto y Ramírez Rojas vs. Perú en que ambos intervinientes fueron contestes en solicitar la modificación de las normas del Decreto Ley $\mathrm{N}^{\circ} 25.475^{[70]}$. Misma situación se presentó en el caso López Álvarez vs. Honduras $^{71}$, en el que se solicitó adecuación a la Convención del Código de Procedimiento Penal, respecto a la prisión preventiva.

Por último, en el caso Penal Miguel Castro Castro vs. Perú, se evidenció una situación disímil a los casos anteriores. La CiDH solicitó, de forma genérica, la modificación de todas aquellas normas que establezcan un obstáculo de hecho para los procesos de investigación general ${ }^{72}$. Mientras que los representantes de las víctimas requirieron la firma y ratificación del

68 Corte IDH, Caso la Cantuta vs. Perú. Cit., punto resolutivo 7.

69 Ibíd., párr. 163.

70 Corte IDH, Caso García Asto y Ramírez Rojas vs. Perú, Sentencia de Excepción Preliminar, Fondo, Reparaciones y Costas de 2005, párr. 277-278.

71 Corte IDH, Caso López Álvarez vs. Honduras, Sentencia de Fondo, Reparaciones y Costas de 2006, párr. 204-205.

72 Corte IDH, Caso Penal Miguel Castro Castro, Sentencia de Fondo, Reparaciones y Costas de 2006, párr. 410. 
Protocolo Facultativo de la Convención contra la Tortura y otros Tratos o Penas Crueles, Inhumanos o Degradantes ${ }^{73}$. En este caso, ni se solicitó ni se declaró la violación al artículo $2^{\circ}$ de la Convención.

Una de las posibles causas de la denegación de la Corte IDH en estos casos puede estar vinculada a que en ninguno de los casos indicados se declaró una violación a la obligación contenida en el artículo $2^{\circ}$ de la CADH.

\subsubsection{Casos posteriores a 2006: Corte IDH no se} pronunció en sus consideraciones de fondo respecto a la violación que genera la solicitud la reparación

Esta argumentación fue esgrimida por la Corte IDH en seis ocasiones ${ }^{74}$ a partir del año 2010 con el caso Chitay Nech y otros vs. Guatemala ${ }^{75}$. En tres casos, la solicitud de reparación fue presentada por los representantes de las víctimas $^{76}$; en dos casos la presentación fue realizada por la $\mathrm{CIDH}^{77}$, y en un caso fue solicitada de forma conjunta.

En este último caso, Atala Riffo y niñas vs. Chile se observó que la CIDH realizó una solicitud genérica en orden a adoptar medidas para prohibir y erradicar la discriminación con base en la orientación sexual $7^{78}$, mientras que los representantes de las víctimas solicitaron que se enviara un mensaje de suma urgencia a un proyecto de ley en ese sentido, pero también la derogación y modificación de toda normativa discriminatoria por orientación sexual ${ }^{79}$.

El argumento que estableció la Corte IDH se relaciona con que en cada caso no se analizó la compatibilidad de una determinada norma con la Convención ni ello fue materia de discusión. Y vinculado a ello, en ningún caso la Corte IDH dictaminó violación del artículo $2^{\circ}$ de la Convención.

A modo de conclusión, el comportamiento de la Corte IDH en este periodo puede tener relación con los cambios a su reglamento que, tal como se señaló, permitieron, por un lado, que los representantes de las víctimas pudieran actuar de forma autónoma en la presentación de sus solicitudes, argumentos y prueba, y por otro que se produjera una duplicidad en la representación

73 Ibíd., párr. 411.

74 Corte IDH, Caso Chitay Nech y otros. vs. Guatemala, Cit.; Caso Atala Riffo vs. Chile, Cit.; Caso Furlán y Familiares vs. Argentina, Cit.; Caso Uzcategui y otros vs. Venezuela, Op. cit.; Caso Corte Suprema de Justicia (Quintana Coello y otros), Cit.; Caso Granier y otros (Radio Caracas Televisión) vs. Venezuela, Cit.

75 Corte IDH, Caso Chitay Nech y otros vs. Guatemala, Cit.

76 Corte IDH, Caso Chitay Nech y otros vs. Guatemala, Cit.; Caso Furlán y Familiares vs. Argentina, Op. Cit.; Caso Granier y otros (Radio Caracas Televisión) vs. Venezuela, Cit.

77 Corte Interamericana de DDHH, Caso Uzcategui y otros vs. Venezuela, Op. Cit.; Caso Corte Suprema de Justicia ("Quintana Coello y otros") vs. Ecuador, Cit.

78 Corte IDH, Caso Atala Riffo y niñas vs. Chile, Cit., párr. 273.

79 Ibíd., párr. 274. 
de las presuntas víctimas con el reglamento del 2003, tal como se muestra a continuación (figura 1).

FIGURA 1. ASPECTOS RELEVANTES DE LOS CAMBIOS REGLAMENTARIOS CORTE IDH ENTRE EL PERIODO 1996 A 2003

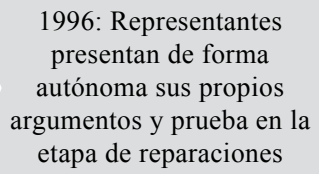

1996: Representantes presentan de forma autónoma sus propios argumentos y prueba en la etapa de reparaciones

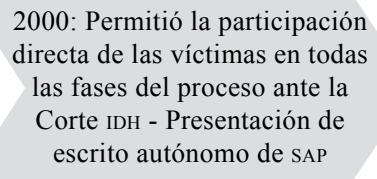
directa de las víctimas en todas las fases del proceso ante la Corte IDH - Presentación de escrito autónomo de SAP

\section{3: CIDH como representante de la presunta víctima}

Fuente: elaboración propia a partir de los cambios en los reglamentos de la Corte IDH

Esto pudo haber generado una especie de periodo de "adaptación" al nuevo modelo de intervención de los representantes de las víctimas, aspecto que no parece justificar la inercia de la Corte IDH en este periodo. Sin embargo, además de la duplicidad en la representación de presuntas víctimas, la CIDH ostenta una duplicidad de roles a partir de esta reforma, ya que, por un lado, desde 1981 la CIDH tiene el carácter de demandante ante el SIDH, y por otro, con esta reforma se le asigna un nuevo rol.

Por otro lado, se observa que el comportamiento de la Corte IDH es consistente en lo referente a la violación del artículo $2^{\circ} \mathrm{CADH}$, ya que, en la mayoría de los casos, la falta de pronunciamiento se debe a la deficiente argumentación de las partes.

No obstante, dentro del mismo periodo hubo sentencias en que si bien existió una solicitud de reparación de orden legislativa, la Corte IDH entregó fundamentos para rechazarla. Esto demuestra una ambivalencia en el comportamiento de la Corte, cuyas causas escapan del análisis de este estudio.

A continuación, se esquematizarán tales casos, clasificando los motivos en cada uno de ellos y los periodos de tiempo en que se generaron mayores denegaciones. No fueron parte de este análisis aquellas sentencias en que la Corte IDH acogió las solicitudes de la medida de reparación en cuestión ya que no eran objeto de esta investigación.

\subsection{Casos en que la Corte IDH no dio lugar a la solicitud de garantías de no repetición en materia legislativa}

Fue posible contabilizar que de las 103 sentencias analizadas en 56 casos la Corte denegó la solicitud de estas reparaciones, entre el periodo de junio de 2003 a diciembre de 2016. Esto equivale al 54\% del total de los casos.

Los argumentos de la Corte IDH pueden clasificarse principalmente en:

1. Pretensión presentada en forma extemporánea; 
2. Falta de fundamentación en la solicitud;

3. Reparación había sido cumplida por el Estado durante el curso del proceso;

4. Reparación había sido solicitada y otorgada en caso anterior;

5. Deficiencias de la normativa no tiene relación con las violaciones de DDHH identificadas en el caso, y,

6. Aplicación de control de convencionalidad.

En cuanto a los periodos de tiempo, se pudo constatar que en el año 2006 y 2009 se produjo la mayor cantidad de casos con rechazo de las peticiones reparatorias (8 casos en cada año) (tabla 1).

TABLA 1. NÚMERO DE PETICIONES RECHAZADAS ENTRE 2003 Y 2016

\begin{tabular}{|c|c|}
\hline Año & Número de casos \\
\hline 2003 & 2 \\
\hline 2004 & 2 \\
\hline 2005 & 4 \\
\hline 2006 & 8 \\
\hline 2007 & 1 \\
\hline 2008 & 1 \\
\hline 2009 & 8 \\
\hline 2010 & 5 \\
\hline 2011 & 3 \\
\hline 2012 & 5 \\
\hline 2013 & 6 \\
\hline 2014 & 4 \\
\hline 2015 & 4 \\
\hline 2016 & 3 \\
\hline Total & 56 \\
\hline
\end{tabular}

Fuente: elaboración propia en base al análisis jurisprudencial.

Esta tendencia también puede tener explicación en los cambios reglamentarios tanto de la Corte IDH como de la CIDH, recordando que sus últimas modificaciones fueron implementadas entre 2009 y 2013. 


\subsubsection{Pretensión presentada en forma extemporánea}

En dos casos la Corte IDH rechazó la pretensión reparatoria porque esta no fue presentada en el momento procesal oportuno, esto es, en la demanda, por lo cual el Tribunal no la consideró por extemporánea ${ }^{80}$. En estos casos se trata más bien de un argumento de orden procesal más que de fondo.

En el caso Torres Millacura vs. Argentina, la CIDH hizo la solicitud en los alegatos finales ${ }^{81}$, mientras que en el caso Argüelles vs. Argentina, fue presentada por Defensores Interamericanos y también se realizó en sus alegatos finales ${ }^{82}$.

Esta argumentación de la Corte IDH se debe a un estricto cumplimiento de las normas procesales. No obstante, sería interesante analizar el impacto en el caso de la solicitud de reparación, puesto que si resultara relevante, se podría dejar pasar la oportunidad de generar un cambio estructural al interior del Estado.

\subsubsection{Falta de fundamentación en la solitud}

Fue posible constatar argumentos vinculados a insuficiente fundamentación y falta de argumentos claros, pertinentes, suficientes, ni en base a prueba específica. Se identificaron $14 \operatorname{casos}^{83}$ en que la Corte IDH sostuvo esta argumentación. Sin embargo, solo en el caso Masacre Santo Domingo vs. Colombia, se alegó la violación del artículo $2^{\circ}$, a lo que la Corte IDH señaló que, si bien los representantes se refirieron a la inexistencia de un marco legal

80 Corte IDH, Caso Torres Millacura vs. Argentina, Cit., párr. 178.; Caso Argüelles y otros vs. Argentina, Cit., párr. 263.

81 Corte IDH, Caso Torres Millacura vs. Argentina, Cit., párr. 174.

82 Corte IDH, Caso Argüelles y otros vs. Argentina, Cit., párr. 259.

83 Corte IDH, Caso Goiburú vs. Paraguay, Sentencia de Fondo Reparaciones y Costas de 2006; Caso Masacre Santo Domingo vs. Colombia, Sentencia de Excepciones Preliminares, Fondo, Reparaciones y Costas de 2012; Caso Granier y Otros (Radio Caracas Televisión) vs. Venezuela, Sentencia de Excepciones Preliminares, Fondo, Reparaciones y Costas de 2015; Caso Familia Barrios vs. Venezuela, Sentencia de Fondo, Reparaciones y Costas de 2011; Caso Escher y otros vs. Brasil, Sentencia de Excepciones Preliminares, Fondo, Reparaciones y Costas de 2009; Caso Garibaldi vs. Brasil, Sentencia de Excepciones Preliminares, Fondo, Reparaciones y Costas de 2009; Caso Hermanos Landaeta Mejías y otros vs. Venezuela, Sentencia de Excepciones Preliminares, Fondo, Reparaciones y Costas de 2014; Caso González y otras (Campo Algodonero) vs. México, Sentencia de Excepciones Preliminares, Fondo, Reparaciones y Costas de 2009; Caso Atala Riffo y Niñas vs. Chile, Sentencia de Fondo, Reparaciones y Costas de 2012; Caso Furlán y Familiares vs. Argentina, Sentencia de Fondo, Reparaciones y Costas de 2012; Caso Corte Suprema de Justicia ("Quintana Coello y otros") vs. Ecuador, Sentencia de Excepciones Preliminares, Fondo, Reparaciones y Costas de 2013; Caso Familia Pacheco Tineo vs. Bolivia, Sentencia de Excepciones Preliminares, Fondo, Reparaciones y Costas de 2013; Caso Comunidad Garífuna de Punta Piedra y sus Miembros vs. Honduras, Sentencia de Fondo, Reparaciones y Costas de 2015, y Caso Comunidad Garifuna Triunfo de la Cruz y sus Miembros vs. Honduras, Sentencia de Fondo, Reparaciones y Costas de 2015. 
adecuado, éstos no presentaron alegatos concretos y específicos ni pruebas, ni tampoco alegaron de qué forma este marco legal adecuado podría haber prevenido los hechos. Por tales motivos, la Corte IDH no analizó los hechos al alero del artículo $2^{\circ}$ de la Convención ${ }^{84}$.

Caso contrario son los casos Goiburú vs. Paraguay, Granier y otros (Radio Caracas Televisión) vs. Venezuela, Escher vs. Brasil, en los cuales no se invocó la violación al artículo $2^{\circ}$ de la Convención, y no se dio lugar a las reparaciones de carácter legislativas por falta de fundamentación. Tanto en el segundo como en el tercer caso la solicitud de reparación fue efectuada por los representantes de las víctimas, a diferencia del primero de ellos, en la se efectuó de forma conjunta con la CIDH.

Este argumento demuestra nuevamente la línea jurisprudencial constante en torno a denegar peticiones no fundadas por parte de la Corte IDH.

\subsubsection{La reparación había sido cumplida por el}

Estado durante el curso del proceso

En nueve $\operatorname{casos}^{85}$ la Corte IDH no se pronunció debido a que la reparación había sido cumplida durante el desarrollo del proceso. En el caso Cinco Pensionistas vs. Perú la Corte IDH observó que: “[...] con posterioridad a la presentación de la demanda, el Estado peruano ha tomado una serie de medidas tendientes al cumplimiento de las pretensiones de la CIDH y de los representantes de las víctimas y sus familiares, a saber: c) la derogación del artículo $5^{\circ}$ del Decreto Ley $\mathrm{N}^{\circ} 25.792^{[86]}$. (...) En cuanto a la pretensión de que se derogara e hiciera cesar "de manera retroactiva" los efectos del artículo 5 del Decreto-Ley No. 25.792, la Corte considera que esta pretensión ya no forma parte de la controversia en el presente caso, puesto que dicho decreto ya fue derogado y, además, se reintegraron los montos de las pensiones dejados

84 Corte IDH, Caso Masacre Santo Domingo vs. Colombia, cit., párr. 317.

85 Corte IDH, Caso Cinco Pensionistas vs. Perú, Sentencia de Fondo, Reparaciones y Costas de 2003; Caso Ticona Estrada y otros vs. Bolivia, Sentencia de Fondo, Reparaciones y Costas de 2008; Caso Tristán Donoso vs. Panamá, Sentencia de Excepciones Preliminares, Fondo, Reparaciones y Costas de 2009; Caso Torres Millacura vs. Argentina, Sentencia de Fondo, Reparaciones y Costas de 2011; Caso Familia Barrios vs. Venezuela, cit.; Caso Nadege Dorzema y otros vs. República Dominicana, Sentencia de Fondo, Reparaciones y Costas de 2012; Caso Liakat Ali Alibux vs. Surinam, Sentencia de Excepciones Preliminares, Fondo, Reparaciones y Costas de 2014; Caso de los Pueblos Indígenas Kuna de Madungandí y Emberá de Bayano y sus Miembros vs. Panamá, Sentencia de Excepciones Preliminares, Fondo, Reparaciones y Costas de 2014; Caso Argüelles y otros vs. Argentina, cit.

86 El 14 de octubre de 1992 se promulgó en Perú el Decreto-Ley N 25792, en el cual se autorizaba a la Superintendencia de Banca y Seguros-SBS- a establecer un Programa de Incentivos para la renuncia voluntaria de sus trabajadores. Esta normativa afectó a las víctimas del caso ya que las pensiones que habían recibido como jubilados desde el 1981 se vieron disminuidas drásticamente y sin previo aviso. 
de percibir por las víctimas, en los términos que las venían percibiendo con anterioridad a que se realizaran las reducciones arbitrarias" $"$.

Este argumento ha sido consistente en el tiempo, constatándose que los casos se presentaron en varias ocasiones dentro del periodo analizado.

\subsubsection{Reparación había sido solicitada y otorgada en caso anterior}

Frente a este argumento, se constataron dos vertientes. La primera son seis $\operatorname{casos}^{88}$ en que la Corte IDH señaló que la reparación ya había sido solicitada y otorgada en un caso anterior, y tan solo la reiteró. Así por ejemplo en el caso "Anzualdo Castro vs. Perú" señaló: "El Tribunal valora lo informado por el Estado, pero recuerda que desde la sentencia dictada en el caso Gómez Palomino ya se había ordenado la referida adecuación de la legislación interna. De este modo, la Corte reitera que el Estado debe adoptar las medidas necesarias para reformar, dentro de un plazo razonable, su legislación penal a efectos de compatibilizarla con los estándares internacionales [...]"89.

La segunda corresponde al caso "J. vs. Perú", en que recordó que la legislación impugnada ya había sido objeto de otros casos, y señaló que no se pronunciaría al respecto ${ }^{90}$.

De los casos identificados llama la atención que cuatro de ellos corresponden a Perú, y que los casos tienen relación con la falta de adecuación del delito de desaparición forzada a los estándares internacionales. Así se constató en el caso "Tenorio Roca y Otros vs. Perú": "En el presente caso, la Corte determinó que el Estado continúa incumpliendo el artículo 2 de la Convención Americana y el artículo III de la Convención Interamericana sobre Desaparición Forzada de Personas en relación con la aplicación del artículo $320^{\circ}$ del Código Penal [...] Por lo tanto, la Corte IDH reitera, tal como lo or-

87 Corte IDH, Caso Cinco Pensionistas vs. Perú, cit.

88 Corte IDH, Caso Anzualdo Castro vs. Perú, Sentencia de Excepciones Preliminares, Fondo, Reparaciones y Costas de 2009, haciendo referencia al Caso Gómez Palomino vs. Perú; Caso Dacosta Cadogan vs. Barbados, Sentencia de Excepciones Preliminares, Fondo, Reparaciones y Costas de 2009, haciendo referencia Caso Boyce vs. Barbados; Caso Chitay Nech y otros vs. Guatemala, Sentencia de Excepciones Preliminares, Fondo, Reparaciones y Costas de 2010, haciendo referencia al Caso Molina Theissen vs. Guatemala; Caso Cabrera García y Montiel Flores vs. México, Sentencia de Excepciones Preliminares, Sentencia de Fondo, Reparaciones y Costas, haciendo referencia al Caso Fernández vs. México y Rosendo Cantú vs. México; Caso Osorio Rivera y Familiares vs. Perú, Sentencia de Excepciones Preliminares, Fondo, Reparaciones y Costas de 2013, haciendo referencia al Caso Gómez Palomino vs. Perú; Caso Tenorio Roca y otros vs. Perú; Sentencia de Excepciones Preliminares, Fondo, Reparaciones y Costas de 2016, haciendo referencia a Gómez Palomino vs. Perú, Anzualdo Castro vs. Perú y Osorio Rivera vs. Perú.

89 Corte IDH, Caso Anzualdo Castro vs. Perú, cit, párr. 303.

90 Corte IDH, Caso J.vs. Perú, Sentencia de Excepciones Preliminares, Fondo, Reparaciones y Costas de 2013, haciendo referencia a los casos Castillo Petruzzi y otros vs. Perú; Loayza Tamayo vs. Perú, y Lori Berenson Mejía vs. Perú. 
denó en los casos Gómez Palomino, Anzualdo Castro y Osorio Rivera, todos contra el Perú, que el Estado debe reformar su legislación penal a efectos de compatibilizarla con la tipificación de acuerdo a los parámetros internacionales en materia de desaparición forzada de personas, con especial atención a lo dispuesto en la Convención Americana y en la Convención Interamericana sobre Desaparición Forzada de Personas. La Corte recalca que dicha reforma legal se ordenó por primera vez hace 11 años, por lo que se insta al Estado a cumplirla a la mayor brevedad"91.

El razonamiento esgrimido por la Corte es coherente en el sentido de que evidencia los constantes incumplimientos de los Estados en estas materias, y consideró que es una especie de herramienta para impulsar las reformas solicitadas.

2.2.5 Deficiencias de la normativa no tiene relación con las violaciones de derechos humanos identificadas en el caso

En el caso "Trabajadores de la Hacienda Verde vs. Brasil", los representantes indicaron que en el país se encontraba tipificado el delito de trata de personas únicamente para fines de explotación sexual, y que, por tanto, y de acuerdo con el Protocolo de Palermo, el Estado debía tipificar el delito en razón a los estándares internacionales.$^{92}$ Frente a esta petición, la Corte IDH consideró que: [...] "el hecho de que la trata esté tipificada únicamente para fines de explotación sexual no tuvo mayor incidencia en el presente caso. A juicio de la Corte los supuestos de la trata de personas ocurrida en el presente caso se encuentran cubiertos por el artículo 207 del Código Penal [...] Este artículo fue efectivamente aplicado en la investigación iniciada luego de la fiscalización del año 1997 y fue objeto del proceso penal iniciado en esa oportunidad. Así, las eventuales deficiencias de la tipificación de la trata de personas no tuvieron consecuencias para la impunidad de las violaciones de DDHH identificadas en el capítulo VIII. Por lo anterior, la Corte estima que no puede acceder a la solicitud de los representantes relativa a que Brasil modifique la definición del delito de trata de personas en su derecho interno" ${ }^{93}$.

Este argumento data de unos de los últimos casos analizados en el estudio, por lo que no se constató si en la actualidad ha vuelto a reiterarse. De todos modos, la Corte IDH establece que los hechos estaban cubiertos por otra norma y por tal motivo, no correspondía modificar la legislación de trata de personas alegada por los representantes. El actuar de los representantes pudo

91 Corte IDH, Caso Tenorio Roca y otros vs. Perú, cit, párr. 303.

92 Corte IDH, Caso Trabajadores de la Hacienda Brasil Verde vs. Brasil, Sentencia de Excepciones Preliminares, Fondo, Reparaciones y Costas de 2016, párr. 452.

93 Corte IDH, Caso Trabajadores de la Hacienda Brasil Verde vs. Brasil, Sentencia de Excepciones Preliminares, Fondo, Reparaciones y Costas de 2016, párr. 455. 
tener su razón aprovechar esta instancia para que la Corte IDH modificara la norma de trata de personas de acuerdo con estándares internacionales, como un mecanismo de litigio estratégico.

\subsubsection{Aplicación del control de convencionalidad}

En cinco $\operatorname{casos}^{94}$ la Corte IDH no ordenó la modificación legislativa solicitada por los representantes de la víctima, haciendo referencia al control de convencionalidad. Cabe tener presente que el control de convencionalidad "fue originalmente diseñado como una doctrina que permite a los jueces nacionales garantizar el derecho a la justicia, la verdad y la reparación de los familiares de las víctimas de graves violaciones a los derechos humanos"95. De este modo, ha sido definido como "una obligación internacional a cargo de todas las autoridades de los Estados parte del Pacto de San José de interpretar cualquier norma nacional (Constitución, ley, decreto, reglamento, jurisprudencia, etcétera) de conformidad con la Convención Americana y, en general, con el corpus juris interamericano; en caso de que exista una manifiesta incompatibilidad entre la norma nacional y el corpus iuris interamericano, las autoridades estatales deberán abstenerse de aplicar la norma nacional para evitar la vulneración de los derechos humanos protegidos internacionalmente. Las autoridades estatales deben ejercer de oficio el control de convencionalidad, pero siempre actuando dentro de sus respectivas competencias y de las regulaciones procesales correspondientes, las cuales se definen en el ámbito interno" 96 .

A partir de estos elementos, la primera referencia se identificó en el caso Radilla Pacheco vs. México. La Corte IDH enfatizó que la obligación de los jueces de realizar este control incluye no sólo el deber de no aplicar las normas contrarias a las disposiciones convencionales, sino también de interpretar la legislación nacional de conformidad con la Convención y los

94 Corte IDH, Caso Radilla Pacheco vs. México, Sentencia de Excepciones Preliminares, Fondo, Reparaciones y Costas de 2009; Caso Fernández Ortega vs. México, Sentencia de Excepciones Preliminares, Fondo, Reparaciones y Costas de 2010; Caso Rosendo Cantú vs. México, Sentencia de Excepciones Preliminares, Fondo, Reparaciones y Costas de 2011; Caso Fontevecchia y D'Amico vs. Argentina, Sentencia de Fondo, Reparaciones y Costas de 2011; Caso López Lone y otros vs. Honduras, Sentencia de Excepción Preliminar, Fondo, Reparaciones y Costas de 2015.

95 GonzÁlez, Pablo. La Doctrina del Control de Convencionalidad a la luz del Principio de Subsidiariedad. En Revista Estudios Constitucionales. Año 15, n. ${ }^{\circ} 1.2017$. ISSN 07180195, p. 60 .

96 Ferrer MacGregor, Eduardo. Control de convencionalidad (sede interna). En Ferrer MacGregor, Eduardo et al. Diccionario de derecho procesal constitucional y convencional. México Poder Judicial de la Federación. Consejo de la Judicatura Federal-unAm. Instituto de Investigaciones Jurídicas. 2014, p. 233. 
principios establecidos en la jurisprudencia de la Corte ${ }^{97}$. Bajo este supuesto, la Corte IDH no consideró necesario ordenar la modificación del contenido normativo solicitado por los representantes de las víctimas ${ }^{98}$. Posteriormente, otros dos casos mexicanos establecieron un idéntico argumento, invocando el caso Radilla Pacheco ${ }^{99}$.

En el caso López Lone vs. Honduras, tanto la CIDH como los representantes de las víctimas solicitaron la adecuación de normas a estándares internacionales del régimen disciplinar aplicado a los jueces ${ }^{100}$. La Corte IDH estableció que "en la aplicación del nuevo régimen disciplinario, las autoridades internas están obligadas a tomar en cuenta las interpretaciones de la CADH realizadas por la Corte Interamericana, en este y otros casos [...] El cumplimiento de dicha obligación no será analizado por esta Corte dentro de la supervisión de cumplimiento de la presente sentencia"101. Llama la atención que la Corte IDH declarara que no supervisaría la aplicación del control de convencionalidad en este caso ${ }^{102}$, sin dar cuenta de las razones de ello. Este aspecto puede tener relación con la dificultad que traería conocer todas las interpretaciones que pudieran realizar las autoridades internas en ese sentido.

Cabe mencionar que en la construcción de la doctrina del control de convencionalidad se evidencia la estrecha relación con el artículo $2^{\circ}$ de la $\mathrm{CADH}^{103}$, tal como se constató en el caso Heliodoro Portugal vs. Panamá: [...] "Precisamente en la adopción de dichas medidas (adecuación normativa a la Convención), es importante destacar que la defensa u observancia de los derechos humanos a la luz de los compromisos internacionales en cuanto a la labor de los operadores de justicia debe realizarse a través de lo que se denomina "control de convencionalidad", según el cual cada juzgador debe velar por el efecto útil de los instrumentos internacionales, de manera de que no quede mermado o anulado por la aplicación de normas o prácticas internas contrarias al objeto y fin del instrumento internacional o del estándar internacional de protección de los derechos humanos" ${ }^{104}$. Por otro lado, en el

97 Corte IDH, Caso Radilla Pacheco Vs. México, cit, citado en: GonzÁlez, Pablo; Reyes NATALIE; ZÚNIIGA, MARCELA. La doctrina de control de convencionalidad y su aplicación en algunas experiencias nacionales. Centro de Estudios de Justicia de las Américas. Santiago, Chile. 2016. ISBN 978-956-8491-31-4. p. 37.

98 Ídem.

99 Corte IDH, Caso Fernández Ortega vs. México, cit., párr. 235, y Caso Rosendo Cantú vs. México, cit., párr. 218.

100 Corte IDH, Caso López Loane vs. Honduras, cit, párr. 304 y 306.

101 Ibíd., párr. 307.

102 Ídem.

103 Henríquez, Miriam; Morales, Mariela. El Control de Convencionalidad: Un balance comparado a 10 años de Almonacid Arellano vs. Chile. Primer Ediciones. Ediciones DER, Santiago, Chile. 2017. ISBN 978-956-9959-03-5, p. 410.

104 Corte IDH, Caso Heliodoro Portugal vs. Panamá, Sentencia de Excepciones Preliminares, Fondo, Reparaciones y Costas de 2008, párr. 180. 
caso Fontevecchia y D'Amico vs. Argentina, la CIDH solicitó la modificación de una serie de normas debido a su incompatibilidad con la Convención, ante lo cual la Corte IDH concluyó que debido a no haber declarado la violación del artículo $2^{\circ}$, no correspondía ordenar tal reparación, estimando suficiente la aplicación del control de convencionalidad ${ }^{105}$.

Una posible explicación para esta argumentación es trasladar a los jueces el cumplimiento de sus sentencias. Esto puede deberse a motivaciones estratégicas, dada las resistencias en la implementación de decisiones interamericanas por parte de algunos Poderes Ejecutivos y Legislativos ${ }^{106}$. Así, puede resultar más eficaz solicitar a los jueces que realicen una interpretación conforme a la Convención, que instar a los demás poderes estatales impulsar una reforma legislativa.

Tal puede ser el caso de México en que la Suprema Corte de Justicia de la Nación, apoyada en normas constituciones y en consideración de las obligaciones que se generaron para el Poder Judicial tras el caso Radilla Pacheco, reconoció por medio de su jurisprudencia la existencia de una obligación para los todos los jueces de realizar un control de convencionalidad en los términos establecidos por el sistema interamericano ${ }^{107}$. Esto puede sustentar que, del análisis realizado, tres de los cinco casos corresponden a México.

No obstante, y en concordancia con Huneeus, a nivel regional no existe un consenso generalizado del estatus que ostentan los estándares internacionales en la justicia nacional, por lo que el mandato a cumplir puede considerarse formalmente débil ${ }^{108}$. Por tal motivo, no se puede dar por establecido que todos los poderes judiciales harán suyos los mandatos de la Corte IDH, tal como sucedió en el caso de México o Chile en relación a la no-aplicación del Decreto Ley sobre Amnistía.

\section{CONCLUSIONES}

El objetivo de esta investigación fue estudiar el comportamiento de la jurisprudencia de la Corte IDH en relación con las GNR que involucran cambios legislativos. Al realizar la sistematización de la jurisprudencia, se optó por comenzar a partir del primer caso resuelto por la Corte IDH en 2003, esto es, Cinco Pensionistas vs. Perú. De esta forma, se podría constatar si existía algún tipo de vinculación con las reformas reglamentarias, más allá del tratamiento argumentativo que dio la Corte en cada caso en particular. Este ejercicio se realizó en todas las sentencias hasta diciembre de 2016.

105 Corte IDH, Caso Fontevecchia y D'Amico vs. Argentina, cit., párr. 113.

106 Huneeus, Alexandra. Cit., p. 509.

107 González, PABlo. Implementación de la Convención Americana de Derechos Humanos en los sistemas jurídicos nacionales: la Doctrina del Control de Convencionalidad. Centro de Estudios de Justicia de las Américas. 2014.

108 Huneeus, Alexandra. Cit., p. 531. 
Del total de casos analizados, se seleccionaron 103 sentencias, identificando que en 56 de ellas la Corte IDH había denegado la solicitud de reparación realizada o por los representantes de la víctima y/o la CIDH, de forma individual o conjunta. De manera adicional, dentro de estos 56 casos, en 12 oportunidades la Corte IDH no se hizo cargo de las presentaciones realizadas por los intervinientes. Estos 12 casos se presentaron en el periodo entre 2003 a 2006, lo que se puede vincular al momento en que los representantes de las víctimas comenzaron a participar de forma autónoma dentro del proceso, puesto que la mayoría de estos casos corresponde a solicitudes realizadas por estos. No obstante, convendría hacer un estudio más en profundidad para analizar de forma más exacta esta posible relación. De todas maneras, la inercia demostrada por la Corte IDH es del todo cuestionable y también convendría estudiar con detalle otro tipo de factores externos.

La mayoría de los casos en que las peticiones reparatorias en comento fueron rechazadas se generaron en 2006 y 2009, hitos que nuevamente pueden estar vinculadas a las reformas reglamentarias que se llevaron a cabo en esos periodos.

Por otra parte, en los 44 casos restantes, la Corte IDH planteó una serie de motivos por los cuales denegó la solicitud de reparaciones, siendo la mayoría de estos vinculados a la falta de fundamentación en las solicitudes. Otro grupo de casos interesantes son aquellos en que se rechazó la petición porque durante el proceso ante la Corte el Estado en cuestión ya había dado cumplimiento a lo requerido.

Luego, se constató la existencia de una serie de casos en que la reparación en cuestión había sido solicitada en un caso anterior, y la Corte IDH tan solo reiteraba. No obstante, en un caso particular, señaló que ya había sido ordenado con anterioridad por lo que no correspondía volver a pronunciarse.

También se constató la presencia de casos en que la Corte IDH no dio lugar a la petición debido a que los jueces debían aplicar el control de convencionalidad de las normas en cuestión, mediante una interpretación conforme a los estándares internacionales en cada materia. Este argumento resulta del todo cuestionable, a pesar de los posibles motivos estratégicos que pudo tener la Corte IDH a la vista al momento de decidir. Para ello es necesario un estudio adicional. En estos casos se constató, además, que existía una importante vinculación a la declaración de violación al artículo $2^{\circ}$, ya que, en cuatro de los seis casos, la Corte IDH determinó tal vulneración.

Otro grupo de casos, la Corte IDH denegó en razón a que se trataba de una solicitud que no había sido objeto de análisis de la sentencia, y además no dictaminó la violación del artículo $2^{\circ}$ de la Convención. En solo dos casos la Corte IDH rechazó la petición por haber sido realizada de forma extemporánea, esto es, en los alegatos finales en audiencia pública, y no en la presentación de la demanda. Este es el único argumento de tipo procesal que se evidenció en el análisis. 
En uno de los últimos casos del periodo analizado, la Corte IDH fue un poco más allá y señaló que las deficiencias de la norma invocada no tuvieron consecuencias en la impunidad de las violaciones detectadas en el caso, por lo cual no dio lugar a la modificación de ésta. Este argumento es novedoso dentro del análisis y abre una arista para abordar en otro estudio.

Dentro del ámbito del análisis realizado es relevante conocer que el 54\% de los casos en que se presenta una solicitud de reparación que tiene relación con cambios legislativos, ha sido rechazado por la Corte IDH, observando tendencias al alza principalmente en los periodos de reformas a los reglamentos del SIDH. Este comportamiento debe ser vinculados con los motivos principales ya señalados, y abren la discusión en relación con mejorar, por un lado, las estrategias de litigio por parte de los representantes de las víctimas como de la CIDH y, por otro, para analizar las nuevas herramientas que ha generado el Sistema, tales como el control de convencionalidad, como una forma de prevenir violaciones. En este último aspecto, podría no ser siempre necesario decretar una medida de reparación en este sentido, sino que instar a los Estados a integrar e interpretar los estándares emanados del sIDH.

Estos resultados también arrojan que la jurisprudencia de la Corte IDH ha establecido argumentos de fondo que debieran ser analizados en detalle, tal como la aplicación del control de convencionalidad y lo generado en el reciente caso de Trabajadores de la Hacienda Verde vs. Brasil, en que no se evidenció una relación en la deficiencia normativa y las violaciones verificadas en el caso.

Finalmente, esta investigación deja abierta la posibilidad de realizar un estudio de los casos en que la Corte IDH dio lugar a las solicitudes de los representantes de las víctimas de la $\mathrm{CIDH}$, vinculadas a reformas legislativas. De este modo, se podría realizar una comparación de los argumentos identificados en este estudio.

\section{REFERENCIAS}

Antrowiak, Thomas M. Remedial Approaches to Human Rights Violations: The InterAmerican Court of Human Rights and Beyond. Seattle University School of Law Digital Commons. 46 Colum. J. Transnat'l. L. 351. 2008: 351-419.

Ayala, Carlos et al. Conference: Reparations in the Inter-American System: A Comparative Approach Conference. American University Law Review. Vol. 56, Issue 6. 2007. ISSN 1375-1468.

Baluarte David, C. y De Vos, Christian. From Judgment to Justice: Implementing International and Regional Human Rights Decisions. Open Society Justice Initiative. ISBN 978-1-936133-33-8. 2010. 204 pp.

Basch, Fernando et Al. La efectividad del Sistema Interamericano de Protección de DDHH: un enfoque cuantitativo sobre su funcionamiento y sobre el cumplimento de sus decisiones. Revista Sur. Edición Vol. 7 - n. ${ }^{\circ}$ 12. 2010. ISSN 1806-6445. 9-35. 
BAZÁn, Víctor. Las reparaciones en el Derecho Internacional de los Derechos Humanos, con particular referencia al Sistema Interamericano. Anuario Argentino de Derecho Internacional de la Asociación Argentina de Derecho Internacional. Editorial Lerner. 2010. ISBN 978-987-1579-37-2. 436 pp.

Beristain, Carlos. Diálogos sobre reparación: qué reparar en casos de violaciones a derechos humanos. Instituto Interamericano de Derechos Humanos. San José, Costa Rica. 2010. IsBN: 978-9978-92-738-0. 530 pp.

Cassel, Douglass. The Expanding Scope and Impact of the reparations awarded by the Interamerican Court of Humans Rights. Revista do Instituto Brasileiro de Direitos Humanos. 2010, Vol. 7, n. ${ }^{\circ}$ 7. 91-107.

Correa, Cristian. Reparaciones y medidas provisionales. Convención Americana sobre Derechos Humanos. Fundación Konrad Adenauer (Ed.). Santiago de Chile. ISBN 978 956-7684-11-3. 2013. 1040 pp.

Cubides Molina, J.M. Reparaciones en la Corte Interamericana de Derechos. Revista Razón Crítica, n. ${ }^{\circ}$ 1. 2016. ISSN: 2500-7807. 52-91.

Ferrer MacGregor, Eduardo. Control de convencionalidad (sede interna). En Ferrer MacGregor, Eduardo et al. Diccionario de derecho procesal constitucional y convencional. México Poder Judicial de la Federación. Consejo de la Judicatura Federal-unam. Instituto de Investigaciones Jurídicas. 2014. 1287 pp.

Galván Puentes, Sofía. Legislative measures as guarantees of non-repetition: a reality in the Inter-American Court, and a possible solution for the European Court. Revista IIDH. Vol. 49. 2009. ISSN 1015-5074. 69-106.

García Ramírez, Sergio. Las reparaciones en el sistema interamericano de protección de los derechos humanos en el Sistema Interamericano de Protección de los Derechos Humanos en el Umbral del Siglo xxi. Memoria del Seminario realizado los días 23 y 24 de noviembre de 1999. Tomo 1. $2^{\circ}$ Edición. Corte Interamericana de Derechos Humanos, San José de Costa Rica. 2003. IsBN: 9977-36-118-5. 1-781.

GonZÁlez, Damián. Do States comply with the compulsory judgments of the Inter-American Court of Human Rights? An empirical study of the compliance with 330 measures. Revista do Instituto Brasileiro de Direitos Humanos. Vol. 13, n. ${ }^{\circ} 13.2013$. ISSN 16771419. 1-28.

González, Pablo. Implementación de la CadH Americana de Derechos Humanos en los sistemas jurídicos nacionales: La Doctrina del Control de Convencionalidad". Centro de Estudios de Justicia de las Américas, 2016.

González, Pablo. La doctrina del control de convencionalidad a la luz del principio de subsidiariedad. Revista Estudios Constitucionales. Año 15, n. ${ }^{\circ}$ 1. 2017. ISSN 07180195. $55-98$.

Hawkins Darren y Jacoby Wade. Partial Compliance: A comparison of the European and Inter- American Courts of Human Rights. Paper presented at the annual meeting of the APSA 2008 Annual Meeting, Hynes Convention Center, Boston, Massachusetts. 2008. 1-50. 
Henríquez, Miriam; Morales, Mariela. El control de convencionalidad: un balance comparado a 10 años de Almonacid Arellano vs. Chile. 1. ${ }^{a}$ ed. Ediciones DER, Santiago, Chile. 2017. ISBN 978-956-9959-03-5, 624 pp.

Huneeus, Alexandra. Courts Resisting Courts: Lessons from the Inter-American Court's Struggle to Enforce Human Rights. Cornell International Law Journal. Vol. 44. Issue. 3. Article 2. 2011 ISSN: 0010-8812. 494-533.

Jiménez de Aréchaga. Responsabilidad Internacional. En Sorensen, M., Manual de Derecho Internacional Público. Editorial Fondo de Cultura Económica. México D.F. 1985. ISBN $9789681602161.819 \mathrm{pp}$.

Loianno, Adelina. Evolución de la doctrina de la Corte Interamericana de Derechos Humanos en materia de reparaciones. Revista Iberoamericana de Derecho Procesal Constitucional, n. ${ }^{\circ}$ 8. 2007. ISSN 1870-8390. 389-413.

Londoño, María Carmelina. Las garantías de no repetición en la jurisprudencia interamericana. Editorial Tirant Lo Blanch México. ISBN 9788490537626. 2014. 407 pp.

Ministerio Público Fiscal de la Ciudad Autónoma de Buenos Aires. Diálogos: el impacto del Sistema Interamericano en el ordenamiento interno de los Estados. Primera Edición Editorial Eudeba. Ciudad Autónoma de Buenos Aires, Argentina. 2013. ISBN 978-950-23-2229-2. 447 pp.

Nash, Claudio. Las reparaciones ante la Corte Interamericana de Derechos Humanos (1988-2007). Segunda edición. Facultad de Derecho Universidad de Chile. Santiago. 2009. ISBN 978-956-19-0636-5. 488 pp.

Organización de las Naciones Unidas, Comisión de Derecho Internacional, Proyecto de Artículos sobre responsabilidad del Estado por Hechos Internacionalmente Ilícitos, adoptados por la CDI en su $53^{\circ}$ periodo de sesiones (A/56/10) y anexado por la AG en su resolución 56/83, de 12 de diciembre de 2001.

Rousset, JAVIER. El concepto de reparación integral en la jurisprudencia de la Corte Interamericana de Derechos Humanos. Revista Internacional de Derechos Humanos. Año I, n. ${ }^{\circ}$ 1. ISSN 2422-7188. 2011. 59-79.

SaAvedra, Pablo. Algunas reflexiones en cuanto al impacto estructural de las decisiones de la Corte Interamericana de Derechos Humanos. En Ferrer Mac-Gregor, Eduardo Von Bogdandy, Armin Morales Antoniazzi, Mariela (Coordinadores). Ius Constitutionale Commune en América Latina. Textos básicos para su comprensión. Colección Constitución y Derechos. Instituto de Estudios Constitucionales del Estado de Querétaro - Max Planck Institute for Comparative Public Law and International Law. México. 2017. ISBN 978-607-7822-32-5. 593 pp.

Shelton, Dinah. The Present Value of Past Wrong. Reparations for Indigenous Peoples. International and Comparative Perspectives. Edited by Federico Lenzerini. Oxford University Press. 2010. ISBN 9780199235605. 622 pp.

Shelton, Dinah. Remedies in International Human Rights Law, Oxford University Press, 2005. 467 pp. 
Schönsteiner, Judith y Javier Couso. La implementación de las decisiones de los órganos del sistema interamericano de Derechos Humanos en Chile: ensayo de un balance. Revista de Derecho Universidad Católica del Norte. Sección de Estudios. Año 2, n. ${ }^{\circ}$ 2. 2015. ISSN 0718-9753. 315-355.

SChönsteiner, Judith. Dissuasive measures and the 'society as a whole': A working theory of reparations in the Inter-American Court of Human Rights. En American University International Law Review, Vol. 23, n..$^{\circ}$. 2015. 127-164.

Schönsteiner, Judith. Hacia mayor seguridad jurídica en la protección regional de los Derechos Humanos: Las reformas procesales en el Sistema Interamericano. Anuario de Derecho Público. Ediciones Universidad Diego Portales. Santiago, Chile. 2010. ISBN 978-956-314-228-0. 291-318.

Ventura, Manuel. Impacto de las reparaciones ordenadas por la Corte Interamericana de Derechos Humanos y aportes a la justiciabilidad de los derechos económicos sociales y culturales. Revista IINDH, Vol. 56. 2012. ISSN 1015-5074. 139-156. 